\title{
PHẪU THUẬT NộI SOI TOÀN Bộ THAY VAN HAI LÁ TRÊN BỆNH NHÂN HẸP VAN HAI LÁ KHÍT CÓ ÁP XE (ABSCESS) VÒNG VAN
}

\section{TÓM TÁT}

Tổn thương van hai lá do viêm nội tâm mạc nhiễm khuẩn là một tình trạng lâm sàng phức tạp, đặc biệt khi đi kèm tổn thương abscess vòng van. Mặc dù phương pháp điều trị phẫu thuật kinh điển qua đường mở xương ức vẫn là ưu tiên hàng đầu, một vài báo cáo về phẫu thuật ít xâm lấn cũng được ghi nhận. Chúng tôi trình bày dưới đây một ca bệnh có tổn thương van hai lá hậu thấp kết hợp với abscess vòng van đã được phẫu thuật bằng phương pháp nội soi toàn bộ tại bệnh viện Tim Hà Nội.

\section{SUMARRY}

Endocarditis mitral valve diseaese was a challenging condition, especially when there was a valve annular abcess. Conventional sternotomy surgery was the standard treatment, while there was a few reports on minimally invasive surgery treatment. We described a clinical case of rheumatic mitral valve disease, accompanied with endocarditis annular abcess, which was successfully treated with totally endoscopic surgery in Hanoi Heart Hospital.

\section{I. ĐẶT VẤN ĐỀ}

Phẫu thuật nội soi thay van hai lá là một kĩ thuât đang được triển khai rộng rãi trên các trung tâm phẫu thuật tim mạch ở Việt Nam và trên thế giới, mang lại nhiều lợi ích cho bệnh nhân. Tuy nhiên những bệnh nhân được chỉ định phẫu thuật nội soi chủ yếu là những trường hợp có tổn thương van hai lá hậu thấp hoặc thoái hóa đơn thuần, có hoặc không đi kèm tổn thương van ba lá cơ năng. Chưa có nhiều báo cáo về phẫu thuật nội soi đối với tổn thương van hai lá do viêm nội tâm mạc nhiễm khuẩn(VNTMNK) như sùi, thủng lá van, abscess vòng van,... Tại nhiều trung tâm, bệnh lý van hai lá do viêm nội tâm mạc nhiễm khuẩn vẫn là một chống chỉ định tương đối đối

\author{
Đặng Quang Huy*, Nguyễn Minh Ngọc*
}

với phẫu thuật nội soi, do sự phức tạp của tổn thương trong mổ cũng như điều trị sau mổ.

Trong bài này, chúng tôi báo cáo một trường hợp bệnh nhân được chẩn đoán hẹp van hai lá khít, trong mổ phát hiện tổn thương abscess vòng van hai lá, đã được phẫu thuật nội soi toàn bộ dựng lại vòng van bằng miếng vá màng tim và thay van hai lá cơ học tại Bệnh viện Tim Hà Nội.

\section{CA LÂM SÀNG}

Bệnh nhân nam, 58 tuổi, tiền sử phát hiện bệnh hẹp van hai lá 6 năm, điều trị nội khoa thường xuyên. Bệnh nhân nhập viện vì mệt, khó thở, phân độ suy tim NYHA II. Siêu âm tim có hình ảnh hẹp van hai lá khít, vôi hóa nhiều tổ chức lá van và dây chằng, Wilkins 10 điểm. Các chỉ số trên siêu âm: kích thước nhĩ trái (LA) $65 \mathrm{~mm}$, kích thước thất trái thì tâm trương (LvDd) $54 \mathrm{~mm}$, phân suất tống máu thất trái $(\mathrm{EF}) 65 \%$, tăng áp lực động mạch phổi nhẹ, thì tâm thu $38 \mathrm{mmHg}$, không có tổn thương van động mạch chủ và van ba lá kèm theo. Điện tim có hình ảnh rung nhĩ, tần số thất 60-70 lần/phút. XQ ngực có hình ảnh bóng tim giãn lớn, chỉ số tim ngực khoảng 0,60 , có hình ảnh tăng tưới máu động mạch phổi.

Bệnh nhân đã được hội chẩn và chỉ định phẫu thuật nội soi toàn bộ thay van hai lá cơ học. Trong mổ, bệnh nhân được gây mê nội khí quản, kê tư thế nghiêng trái 30 độ. Thiết lập tuần hoàn ngoài cơ thể qua mạch ngoại vi: đặt cannula động mạch (ĐM) đùi gián tiếp qua đoạn mạch số 8 (B. Braun Uni-Graft), và đặt cannula tĩnh mạch (TM) chủ trên và dưới qua $\mathrm{TM}$ cảnh trong phải và $T M$ đùi phải theo phương pháp Seldinger. Sử

\footnotetext{
* Bệnh viện Tim Hà Nội

Ngưòi chịu trách nhiệm khoa học: Đặng Quang Huy

Ngày nhận bài: 02/08/2020 - Ngày Cho Phép Đăng: 04/09/2020

Phản Biện Khoa học: PGS.TS. Đặng Ngọc Hùng PGS.TS. Nguyễn Hũu U'ơcc
} 
dụng cannula $\mathrm{TM}$ chủ trên và cannula $\mathrm{TM}$ chủ dưới kích cỡ $21 \mathrm{Fr}$ (Medtronic Bio-medicus).

Phẫu thuật nội soi toàn bộ được tiến hành qua 04 lỗ trên thành ngực.

- 01 1ỗ 5mm cho dụng cụ cặp ĐM chủ đường nách giữa khoang liên sườn $\mathrm{IV}$

- 01 đường mở ngực 40mm cho dụng cụ phẫu thuật (cả 2 tay) ở đường nách trước khoang liên sườn $\mathrm{V}$

- 01 1ỗ $5 \mathrm{~mm}$ cho camera nội soi ở đường nách giữa khoang liên sườn $\mathrm{V}$

- 01 1ỗ $5 \mathrm{~mm}$ cho dẫn lưu tim trái đường nách giữa khoang liên sườn VI

Bơm $\mathrm{CO} 2$ vào khoang màng phổi với lưu lượng 1 lít/phút. Chạy máy tuần hoàn ngoài cơ thể (THNCT) toàn bộ lưu lượng. Đặt kim gốc động mạch chủ. Cặp ĐM chủ. Bảo vệ cơ tim xuôi dòng bằng dung dịch Custodiol. Mở nhĩ trái, bộc lộ van hai lá qua đường rạch ở rãnh nhĩ thất, sử dụng dụng cụ vén nhĩ Aesculap Valve XS (B.Braun). Thăm dò thấy nhĩ trái giãn lớn, không có huyết khối trong nhĩ trái.

Van hai lá tổn thương hậu thấp nặng, vôi hóa nhiều vùng $\mathrm{P} 3$ lá sau. Vùng $\mathrm{P} 2$ có tổn thương abscess vòng van cũ, kích thước khoảng $10 \mathrm{~mm}$. Trên van hai lá không có tổn thương sùi mới. Tiến hành cắt bỏ toàn bộ lá trước van hai lá. Lấy vôi lá sau, để lại một phần lá van và dây chằng lá sau.

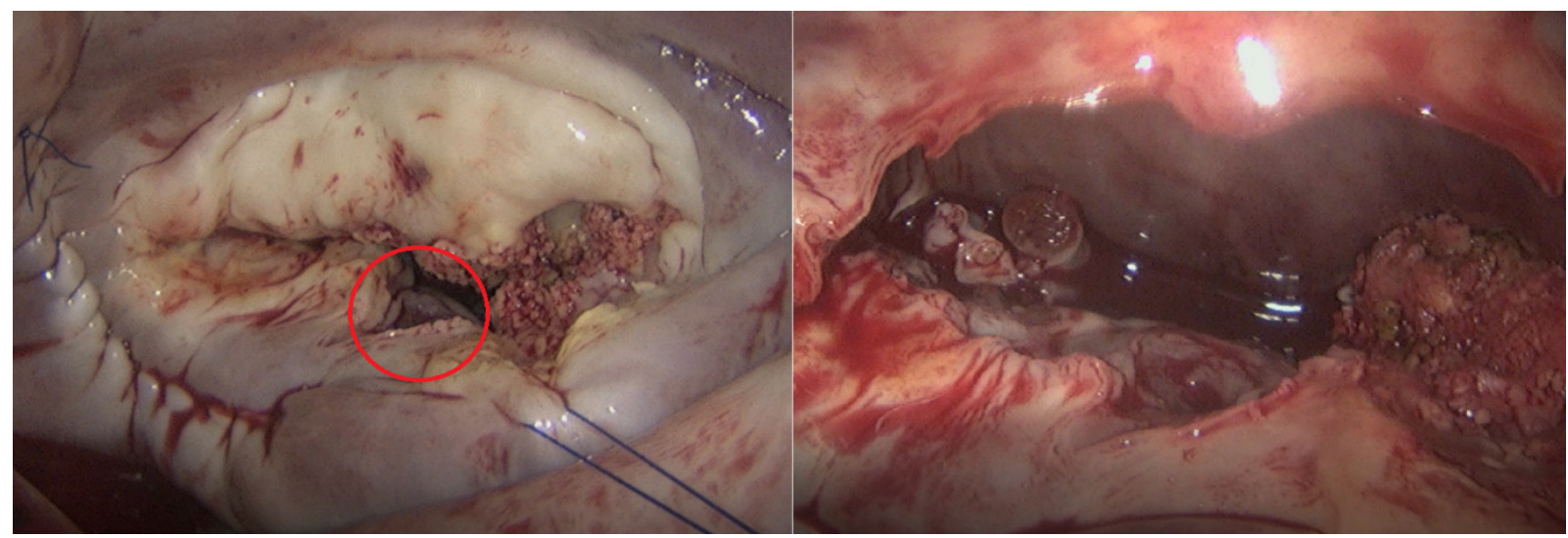

Hình 1: Ổ abscess vòng van trước và sau khi cắt van

Lấy mẫu bệnh phẩm lá van để nuôi cấy vi khuẩn. Tổn thương abscess vòng van được xử trí bằng miếng vá màng tim nhân tạo Xenosure (Lemaitre, MA, USA), khâu vắt bằng chỉ Prolene $5 / 0$ (Johnson \& Johnson, USA). Khâu thu nhỏ nhĩ trái và đóng tiểu nhĩ. Thay van hai lá cơ học On-X số 31/33 (Cryolife, NW, USA) bằng toàn bộ các mũi chỉ chữ U có đệm pledget.

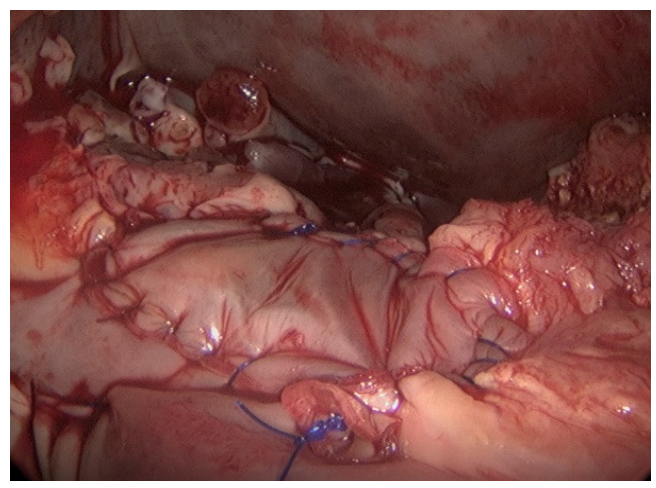

Hình 2: Tạo hình lại vòng van bằng miếng vá màng tim nhân tạo XenoSure 
Đóng lại nhĩ trái. Thả cặp ĐM chủ cho tim đập lại. Kiểm tra cầm máu, đặt các dẫn lưu, rút các cannula động tĩnh mạch và đóng các vết mổ. Thời gian cặp ĐM chủ 117 phút, thời gian chạy máy THNCT 208 phút.

Sau phẫu thuật, bệnh nhân được rút ống nội khí quản sau 14 giờ, không phải sử dụng thuốc vận mạch. Bệnh nhân nằm hồi sức 3 ngày và ra viện sau 30 ngày, sau 4 tuần điều trị kháng sinh dự phòng. Kết quả cấy máu và cấy tổ chức van không có vi khuẩn. Siêu âm sau mổ chức năng tim tốt, van hai lá cơ học nằm đúng vị trí, hoạt động bình thường, không có hở cạnh van. Theo dõi tái khám sau 3 tháng và 6 tháng không có dấu hiệu nhiễm trùng tái phát.

\section{BÀN LUẬN}

Tổn thương van hai lá (bao gồm cả những tổn thương ở lá van, vòng van và tổ chức dưới van) trong bệnh lý VNTMNK là một tình trạng lâm sàng phức tạp, cần được theo dõi và điều trị lâu dài. Phẫu thuật sửa van hoặc thay van thường được chỉ định trên những bệnh nhân có tổn thương van hai lá nặng[1]. Điều trị nội khoa bằng kháng sinh trước phẫu thuật là cần thiết, trừ những trường hợp tổn thương van quá nặng gây suy tim cấp. Mặc dù kết quả điều trị ngày càng được cải thiện, tuy nhiên tỉ lệ biến chứng và tử vong đối với các phẫu thuật van tim do VNTMNK vẫn còn tương đối cao, đặc biệt là ở các nước đang phát triển nơi tình trạng kháng kháng sinh đang ngày càng phổ biến[2]. Những tổn thương van tim trong bệnh viêm nội tâm mạc nhiễm khuẩn thường phức tạp và cần được xử trí triệt để trong mổ, do đó ở nhiều các trung tâm trên thế giới và trong nước, phẫu thuật kinh điển qua đường mở xương ức vẫn là cách tiếp cận được ưu tiên hàng đầu. Không có nhiều những báo cáo về kết quả phẫu thuật ít xâm lấn hoặc phẫu thuật nội soi điều trị bệnh van hai lá do VNTMNK, thường chỉ là những báo cáo về case lâm sàng[3]. Tại trung tâm của chúng tôi, đối với bệnh lý VNTMNK, phẫu thuật kinh điển qua đường mở xương ức vẫn là chỉ định tuyệt đối.
Tuy nhiên trong trường hợp bệnh nhân này, những thăm dò trước mổ trên siêu âm và cận lâm sàng không cho thấy bằng chứng của tình trạng VNTMNK, nhiều khả năng tổn thương abscess vòng van của bệnh nhân là tổn thương cũ, trong một đợt diễn biến cấp tính của bệnh trước đó. Trong báo cáo của David (2007), trong số 183 bệnh nhân được phẫu thuật có abscess vòng van, có $40 \%$ là được chẩn đoán trong mổ[4]. Vì vậy, đối với những thông tin trước mổ của bệnh nhân này, chúng tôi vẫn chỉ định phẫu thuật nội soi thay van hai lá như một trường hợp thấp tim thông thường.

Tổn thương abcess vòng van hai lá là một yếu tố tiên lượng nặng đối với bệnh nhân được phẫu thuật van hai lá do VNTMNK. Theo Langiulli (2004), tỉ lệ tử vong trên bệnh nhân abscess vòng van cao gấp đôi so với bệnh nhân VNTMNK không có abscess vòng van (29\% so với 14\%)[5].

Để sửa chữa tổn thương này, Carpentier đã đề xuất phương pháp bao gồm: (1) cắt bỏ sạch khối abcess và các tổn thương xung quanh; (2) tái tao lại vòng van bằng miếng vá màng tim và (3) thay van hai lá nhân tạo[6]. Phương pháp này được sự đồng thuận và áp dụng rộng rãi ở các trung tâm phẫu thuật tim mạch trên thế giới. Theo báo cáo của David (2007), trong thời gian theo dõi 10 năm, tỉ lệ tử vong của các bệnh nhân có abscess vòng van là $25 \%$, và $72 \%$ không phải phẫu thuật lại do tái phát[4]. Đối với ca bệnh này, chúng tôi cũng sử dụng phương pháp tương tự. Mặc dù có khó khăn về mặt kĩ thuật khi thực hiện qua đường mổ nội soi nhưng với phương tiện bộc lộ tốt (Hệ thống Camera nội soi Aesculap và bộ dụng cụ vén nhĩ Aesculap Valve XS, B.Braun, Germany) và kinh nghiệm trong phẫu thuật nội soi, chúng tôi vẫn có thể hoàn thành sửa chữa các tổn thương trong thời gian cặp chủ không quá dài (117 phút, tương ứng với một liều dung dịch bảo vệ cơ tim Custodiol).

Bệnh nhân sau mổ có quá trình hồi phục ổn định và không có biến chứng sau mổ. Một liệu trình kháng sinh dự phòng phổ rộng được chỉ 
định trong 4 tuần trước khi xuất viện, các kết quả cấy máu và cấy bệnh phẩm đều âm tính. Chúng tôi cho rằng tiên lượng lâu dài của ca bệnh này là tương đối tốt do tổn thương VNTMNK là tổn thương cũ, và không có tình trạng nhiễm trùng trước và sau phẫu thuật. Theo dõi trong ngắn hạn (6 tháng) bệnh nhân ổn định và không có nhiễm trùng tái phát. Tuy nhiên bệnh nhân này vẫn cần phải được theo dõi sát sao và lâu dài.

Câu hỏi đặt ra là: đối với sự phát triển về kĩ thuật và các phương tiện hỗ trợ cho mổ nội soi hiện nay, có nên mở rộng chỉ định phẫu thuật nội soi (hoặc ít xâm lấn) đối với các trường hợp VNTMNK hay không? Chúng tôi cho rằng với những dữ liệu và báo cáo lâm sàng hạn chế hiện nay, điều này là không nên, vì điều quan trọng nhất trong điều trị bệnh van tim do VNTMNK là xử trí triệt để tổn thương để giảm thiểu nguy cơ tái phát, và phẫu thuật kinh điển qua đường mở xương ức vẫn là lựa chọn ưu việt hơn.

Tuy nhiên, một số báo cáo cũng cho thấy kết quả tích cực của phầu thuật ít xâm lấn điều trị bệnh van tim do VNTMNK. Trong báo cáo của F.Fleissner và cs (2018), 44 trường hợp đã được phẫu thuật ít xâm lấn qua đường mở ngực phải để điều trị bệnh van hai lá do VNTMNK. Kết quả chỉ có 1 trường hợp tử vong và 1 trường hợp tái phát phải phẫu thuật lại[7]. Trong tương lai, khi có thêm nhiều bằng chứng lâm sàng hơn, chúng tôi cho rằng hoàn toàn có thể mở rộng chỉ định phẫu thuật nội soi hoặc ít xâm lấn để điều trị bệnh lý này.

\section{KẾT LUẬN}

Trên đây là báo cáo về một case lâm sàng hẹp van hai lá khít có abscess vòng van cũ đã được điều trị thành công bằng phương pháp phẫu thuật nội soi toàn bộ. Tổn thương van tim do VNTMNK là một tình trạng lâm sàng phức tạp, cần được điều trị triệt để, trong đó abcess vòng van là một yếu tố tiên lượng nặng. Với không nhiều bằng chứng lâm sàng về lợi ích của phẫu thuật nội soi (hoặc ít xâm lấn) đối với nhóm bệnh nhân này, chúng tôi cho rằng một khi tình trạng VNTMNK được chẩn đoán trước mổ, phẫu thuật kinh điển vẫn là lựa chọn tối ưu.

\section{TÀI LIÊU THAM KHẢO}

1. Farag, M., et al., Surgery for Infective Endocarditis: Outcomes and Predictors of Mortality in 360 Consecutive Patients. Med Sci Monit, 2017. 23: p. 3617-3626.

2. Habib, G., et al., 2015 ESC Guidelines for the management of infective endocarditis: The Task Force for the Management of Infective Endocarditis of the European Society of Cardiology (ESC). Endorsed by: European Association for Cardio-Thoracic Surgery (EACTS), the European Association of Nuclear Medicine (EANM). Eur Heart J, 2015. 36(44): p. 3075-3128.

3. Van Praet, K.M., et al., Minimally invasive approach for infective mitral valve endocarditis. Ann Cardiothorac Surg, 2019. 8(6): p. 702-704.

4. David, T.E., et al., Surgical treatment of paravalvular abscess: long-term results. Eur $\mathrm{J}$ Cardiothorac Surg, 2007. 31(1): p. 43-8.

5. Langiulli, M., et al., Comparison of outcomes in patients with active infective endocarditis with versus without paravalvular abscess and with and without valve replacement. Am J Cardiol, 2004. 94(1): p. 136-7.

6. Carpentier, A.F., D.H. Adams, and F. Filsoufi, Carpentier's Reconstructive Valve Surgery: From Valve Analysis to Valve Reconstruction 1st Edition. 2010, Elsevier Saunders.

7. Fleissner, F., et al., Minimally Invasive Surgery in Mitral Valve Endocarditis. Thorac Cardiovasc Surg, 2019. 67(8): p. 637-643. 